\title{
An electron-transporting host material compatible with diverse triplet emitters used for highly efficient red- and green-electrophosphorescent devices $\dagger$
}

\author{
Tsyr-Yuan Hwu, ${ }^{a}$ Tsung-Cheng Tsai, ${ }^{b}$ Wen-Yi Hung, ${ }^{* b}$ Sheng-Yuan Chang, ${ }^{c}$ \\ Yun Chi, ${ }^{* c}$ Mei-Hsin Chen, ${ }^{d}$ Chih-I Wu, ${ }^{d}$ Ken-Tsung Wong ${ }^{* a}$ and \\ Liang-Chen $\mathrm{Chi}^{a}$
}

Received (in Cambridge, UK) 9th May 2008, Accepted 14th July 2008

First published as an Advance Article on the web 2nd September 2008

DOI: $10.1039 / b 807954 d$

\begin{abstract}
A bifluorene analogue, T2N, containing a pyridyl moiety serves as both a host and an efficient electron-transporting material that is compatible with various heavy metal-containing red (Ir, $\mathrm{Ru}, \mathrm{Os}$, and Pt) and green (Ir) phosphors for highly efficient phosphorescent OLEDs possessing simple device architectures.
\end{abstract}

Dispersing transition metal-containing phosphors into suitable host materials can reduce the quenching processes associated with the relatively long lifetimes and triplet-triplet annihilations of triplet excited states. Using this approach, both singlet and triplet excitons can be harvested efficiently, making it possible to prepare organic light-emitting devices (OLEDs) exhibiting 100\% internal efficiency. ${ }^{1}$ Most of the efficient host materials reported were hole-transporting (HT) compounds - in particular, carbazole-based organoaryls; ${ }^{2}$ electron-transporting (ET) host materials are relatively rare. ${ }^{3}$ Electrophosphorescent devices incorporating HT-type host materials normally require sophisticated configurations, incorporating various functional materials, including transporting and blocking layers, to facilitate efficient exciton confinement on the phosphors. Such devices are not sufficiently cost-effective to compete with other contemporary flatpanel display technologies. In contrast, ET-type host materials are capable of being fabricated into efficient OLEDs with simplified device structures. Thus, the development of efficient ET-type host materials is in high demand for providing extra flexibility in designing device configurations. In previous studies, we used spiro-configured bifluorenes as hosts for red electrophosphorescent devices; ${ }^{4}$ the maximum electroluminescence (EL) quantum efficiencies observed were substantially higher than that obtained when using the carbazole-based host

\footnotetext{
${ }^{a}$ Department of Chemistry, National Taiwan University, Taipei, Taiwan 106. E-mail: kenwong@ntu.edu.tw; Fax: + 886233661667 ; Tel: +886233661665

${ }^{b}$ Institute of Optoelectronic Sciences, National Taiwan Ocean

University, Keelung, Taiwan 202.

E-mail:wenhung@mail.ntou.edu.tw

${ }^{c}$ Department of Chemistry, National Tsing Hua University, Hsinchu,

Taiwan 300.E-mail: ychi@mx.nthu.edu.tw

${ }^{d}$ Department of Electrical Engineering and Graduate Institute of Electro-optical Engineering, National Taiwan University, Taipei,

Taiwan 106

$\dagger$ Electronic supplementary information (ESI) available: Synthesis and characterization of new compounds; UPS traces of T2 and T2N. See DOI: 10.1039/b807954d
}

4,4'-bis(9-carbazolyl)-2,2'-biphenyl (CBP). ${ }^{2 a, 3 a}$ We suspected that if we implanted a $\pi$-electron-deficient heteroarene into the bifluorene backbone, the resulting molecule would have a relatively higher electron affinity, which would facilitate injection and transport of electrons from the cathode. In this paper, we report a new 4-azafluorene-based host, T2N (Scheme 1), in which a nitrogen atom has been implanted into the backbone of a bifluorene unit, exhibiting modified electronic properties. This new material serves as a suitable ET host for a range of distinctive green and red emitters possessing wide structural features, giving electrophosphorescent devices with low turnon voltages and remarkable efficiencies.

Scheme 1 depicts our synthetic pathway toward T2N. Suzuki coupling of the pyridine-containing amide $\mathbf{1}$ and the fluorene boronic ester 2 afforded the amide 3 in $68 \%$ isolated yield. The azafluorenone 4 was obtained in $77 \%$ yield through intramolecular cyclization upon treating 3 with LDA. The Grignard reaction of $\mathbf{4}$ with $p$-tolylmagnesium bromide and subsequent Friedel-Crafts alkylation provided T2N in $42 \%$ yield.

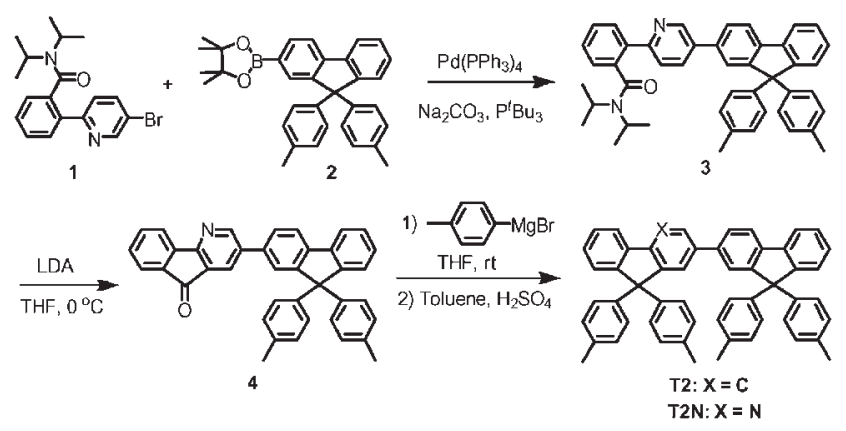

Scheme 1 Synthesis of T2N.

The introduction of a pyridyl moiety as a constituent of the $\pi$ conjugated backbone had an interesting effect on the physical properties of $\mathbf{T} 2 \mathbf{N}$ relative to those of its pure-hydrocarbon counterpart, $\mathbf{T 2} .^{5}$ The fluorescence and absorption spectra of T2N in $\mathrm{CH}_{2} \mathrm{Cl}_{2}$ solution (Fig. 1) exhibited limited red shifting relative to those of the parent bifluorene $\mathbf{T} 2$. The phosphorescence of $\mathbf{T} 2 \mathbf{N}$ was also measured at $77 \mathrm{~K}$ (in EtOH). The difference between the fluorescence $(377 \mathrm{~nm})$ and phosphorescence $(506 \mathrm{~nm})$ spectra corresponds to an exchange energy of $c a$. $1.2 \mathrm{eV}$ between the singlet and triplet states of $\mathbf{T} 2 \mathbf{N}$. The triplet energy of $2.45 \mathrm{eV}$ (defined as the $0-0$ transition in the 


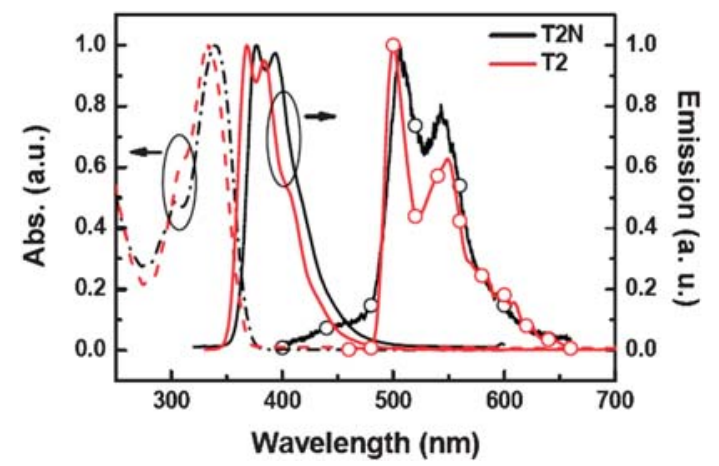

Fig. $1 \mathrm{UV}-\mathrm{Vis}$, fluorescence (room temperature in $\mathrm{CH}_{2} \mathrm{Cl}_{2}$ solution), and phosphorescence (77 K, EtOH) spectra of T2N (black) and T2 (red).

phosphorescent spectrum) of $\mathbf{T} 2 \mathbf{N}$ is similar to that of $\mathbf{T} 2$ (2.48 eV). ${ }^{4}$ These results indicate that the photophysical properties are slightly altered upon introducing the pyridyl moiety onto the conjugated chromophore.

The highest occupied molecular orbital (HOMO) energy level $(-5.75 \mathrm{eV})$ of $\mathbf{T} \mathbf{2 N}$, taken from ultraviolet photoelectron spectroscopy (UPS) measurements (Fig. S-1, ESI $\dagger$ ), and the corresponding lowest unoccupied molecular orbital (LUMO) energy $(-2.50 \mathrm{eV})$ derived by subtracting the HOMO energy from the UV-Vis absorption edge $(3.25 \mathrm{eV})$. The energy band diagrams of $\mathbf{T} 2$ and $\mathbf{T} 2 \mathbf{N}$ can be obtained from the UPS data (ESI $\dagger$ ). The main features of occupied molecular orbitals of T2N at $4.6 \mathrm{eV}, 7 \mathrm{eV}$, and $9 \mathrm{eV}$ below the Fermi level all shift toward lower binding energy with respect to that of $\mathbf{T} 2$. The data indicate that the energy level of HOMO, as well as LUMO, of the T2N is lower than those of T2 (HOMO: $-5.65 \mathrm{eV}$, LUMO: $-2.35 \mathrm{eV}$ ). Thus, the electronic structure of the parent bifluorene $\mathbf{T} \mathbf{2}$ was perturbed after embedding the nitrogen atom into the parent hydrocarbon backbone. This modification decreased both the HOMO and LUMO energy levels; in particular, the low LUMO energy level of T2N is a crucial feature for reducing the energy barrier for electron injection from the cathode. In addition, the presence of the C9 $p$-tolyl substituents provided high thermal and morphological stability to the thin films of $\mathbf{T} \mathbf{2 N}$, as indicated by their high decomposition ( $5 \%$ weight loss) temperatures $\left(T_{\mathrm{d}}=340{ }^{\circ} \mathrm{C}\right)$ and moderately high glass transition temperatures $\left(T_{\mathrm{g}}=\right.$ $144{ }^{\circ} \mathrm{C}$ ). The relatively high triplet energy of $\mathbf{T} 2 \mathrm{~N}$ suggests that it might be a suitable host material for yellow to red phosphors. We employed a relatively simple configuration for fabricating OLED devices: ITO/polyethylenedioxythiophene/

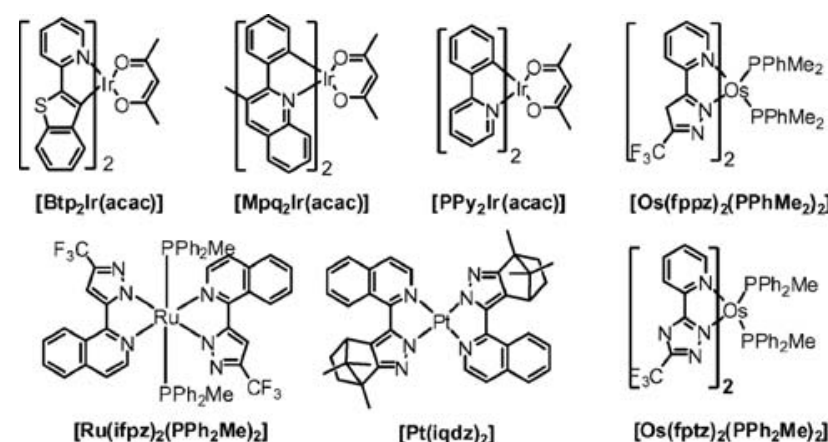

Scheme 2 Structures of the heavy metal complexes used in this study.

polystyrene sulfonate (PEDOT:PSS, $30 \mathrm{~nm}) / 4,4^{\prime}, 4^{\prime \prime}-\operatorname{tri}(N$ carbazolyl)triphenylamine (TCTA, $40 \mathrm{~nm}) / \mathbf{T 2 N}$ :dopant $(25$ $\mathrm{nm}) / \mathbf{T} 2 \mathrm{~N}(35 \mathrm{~nm}) / \mathrm{LiF}(0.5 \mathrm{~nm}) / \mathrm{Al}$; TCTA functioned as the HT layer, while T2N functioned as both host and ET materials. The low barrier between the HOMO energy levels of TCTA $(-5.6 \mathrm{eV})$ and T2N $(-5.75 \mathrm{eV})$ allowed direct hole injection from TCTA into T2N. The electrons injected from the $\mathbf{T} 2 \mathbf{N}$ layer were trapped by the dopants dispersed within it, recombining with the holes to generate excitons directly, allowing efficient confinement of the emissive excitons within the emissive layer. We used the heavy metal complexes ${ }^{6}$ (Scheme 2) Os(fptz) $)_{2}\left(\mathrm{PPh}_{2} \mathrm{Me}\right)_{2}, \mathrm{Os}(\mathrm{fppz})_{2}\left(\mathrm{PPhMe}_{2}\right)_{2}, \mathrm{Btp}_{2} \mathrm{Ir}-$ (acac), $\mathrm{Mpq}_{2} \operatorname{Ir}(\mathrm{acac}), \mathrm{Pt}(\mathrm{iqdz})_{2}$, and $\mathrm{Ru}(\mathrm{ifpz})_{2}\left(\mathrm{PPh}_{2} \mathrm{Me}\right)_{2}$ as red dopants and $\mathrm{PPy}_{2} \operatorname{Ir}(\mathrm{acac})$ as a green dopant for the T2N layer. Table 1 summarizes the electroluminescence characteristics of the resulting devices.

As indicated in Fig. 2(a), these devices turned on at low voltages (2.9-5.7 $\mathrm{V}$ at a brightness of $0.1 \mathrm{~cd} \mathrm{~m}^{-2}$ ), probably because the HOMO and LUMO energy levels of T2N matched well with those of TCTA and cathode, leading devices to have high current density (Fig. 2(b)). All of the devices exhibited high external quantum efficiencies $\left(\eta_{\text {ext }}>10 \%\right.$; Fig. 3(a)), and the EL spectra revealed pure dopant emissions (Fig. 3(b)). These results suggest that our present device structure, incorporating T2N as an ET-type host, generally provides highefficiency OLEDs for red phosphors featuring diverse metal centres, and $\mathbf{T} 2 \mathbf{N}$ can also accommodate a green emitter $\left[\mathrm{PPy}_{2} \operatorname{Ir}(\mathrm{acac})\right]$ efficiently.

Among these devices, the highest external quantum efficiency $\left(15.5 \%\right.$ at $0.1 \mathrm{~mA} \mathrm{~cm}^{-2}$ ) and highest brightness (29 700 $\mathrm{cd} \mathrm{m}^{-2}$ at $\left.19 \mathrm{~V}\right)$ with saturated red emission of CIE1931 coordinates $(0.68,0.32)$ were obtained when using $9 \mathrm{wt} \%$ $\mathrm{Os}(\mathrm{fptz})_{2}\left(\mathrm{PPh}_{2} \mathrm{Me}\right)_{2}$ as the dopant. To the best of our knowledge, this is the highest efficiency reported for a red

Table 1 Electroluminescence characteristics of devices incorporating various red and green dopants

\begin{tabular}{|c|c|c|c|c|c|c|}
\hline Dopant (wt\%) & $V_{\text {on }}{ }^{a} / \mathrm{V}$ & $L_{\max } / \mathrm{cd} \mathrm{m}^{-2}$ & $I_{\max } / \mathrm{mA} \mathrm{cm}^{-2}$ & $\eta_{\text {ext } \max }\left(\%, \mathrm{~cd} \mathrm{~A}^{-1}\right)$ & $\eta_{\mathrm{p} \max } / \mathrm{lm} \mathrm{W}^{-1}$ & $\operatorname{CIE}(x, y)$ \\
\hline $\mathrm{Btp}_{2} \operatorname{Ir}(\mathrm{acac})(5 \%)$ & 3.2 & $8600(18 \mathrm{~V})$ & 1330 & $10.4,8.1$ & 6.8 & $0.68 ; 0.32$ \\
\hline $\mathrm{Mpq}_{2} \operatorname{Ir}(\mathrm{acac})(9 \%)$ & 4.7 & $23300(19.5 \mathrm{~V})$ & 1180 & $13.7,13.3$ & 9.3 & $0.66 ; 0.34$ \\
\hline $\mathrm{Os}(\mathrm{fptz})_{2}\left(\mathrm{PPh}_{2} \mathrm{Me}\right)_{2}(9 \%)$ & 5.5 & $29700(19 \mathrm{~V})$ & 1150 & $15.5,11.4$ & 6.9 & $0.68 ; 0.32$ \\
\hline $\mathrm{Os}(\mathrm{fppz})_{2}\left(\mathrm{PPhMe}_{2}\right)_{2}(9 \%)$ & 5.7 & $22000(19.5 \mathrm{~V})$ & 1250 & $13,9.7$ & 6.8 & $0.68 ; 0.32$ \\
\hline $\operatorname{Pt}(\text { iqdz })_{2}(9 \%)$ & 3.8 & $15000(19.5 \mathrm{~V})$ & 1200 & $10.2,12.3$ & 9.4 & $0.64 ; 0.36$ \\
\hline $\mathrm{Ru}(\text { ifpz })_{2}\left(\mathrm{PPh}_{2} \mathrm{Me}\right)_{2}(6 \%)$ & 5.6 & $4200(19.5 \mathrm{~V})$ & 800 & $11.2,7.9$ & 6.3 & $0.68 ; 0.32$ \\
\hline $\mathrm{PPy}_{2} \operatorname{Ir}(\mathrm{acac})(10 \%)$ & 2.9 & $69000(17 \mathrm{~V})$ & 1600 & $12.3,45$ & 38 & $0.48 ; 0.52$ \\
\hline
\end{tabular}



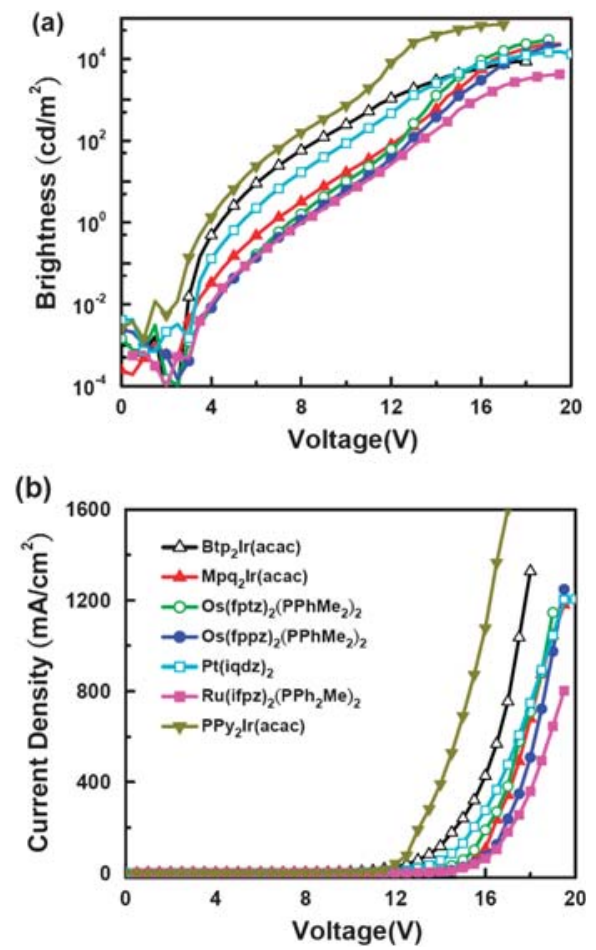

Fig. 2 (a) Brightness vs. voltage and (b) current density vs. voltage characteristics of devices having an identical structure but incorporating different dopants.
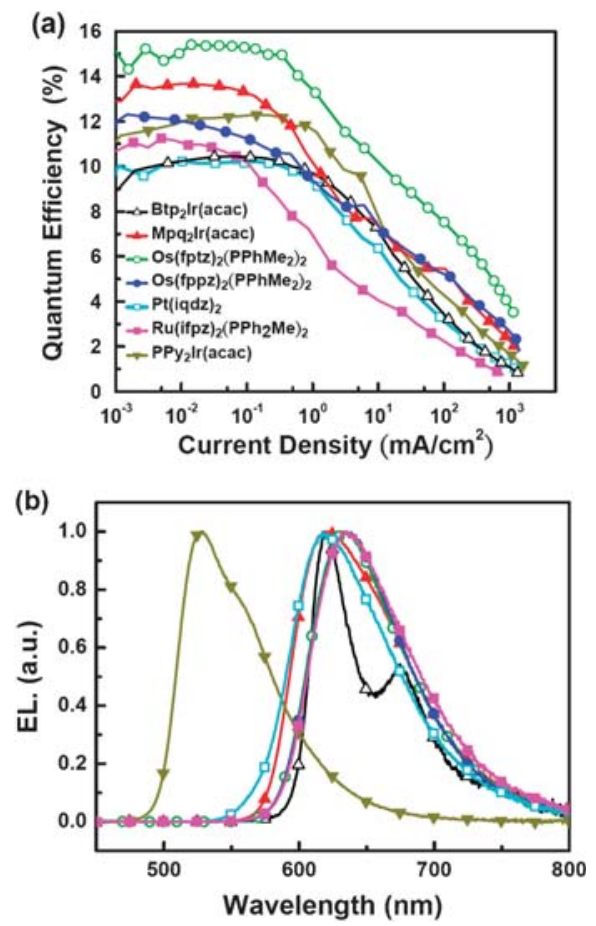

Fig. 3 (a) External quantum efficiencies (EQEs) and (b) EL spectra of devices incorporating various dopants.

phosphorescent OLED employing an ET-type host material. We note that although the efficiency dropped upon increasing the brightness, ${ }^{7}$ this device retained its high efficiency $(10 \%$ at $18 \mathrm{~mA} \mathrm{~cm}^{-2}$ ) at a brightness of $1000 \mathrm{~cd} \mathrm{~m}^{-2}$.
In summary, we have synthesized a novel host material, T2N, featuring an electron-deficient pyridyl moiety embedded into a bifluorene backbone. The electronic behaviour of this chromophore was modulated significantly relative to that of its parent compound, rendering $\mathbf{T 2 N}$ suitable for use as an electron-transporting host material compatible with various heavy metal-containing red and green phosphors. Most importantly, taking advantage of the dual functions of T2N, high-efficiency red- and green-phosphorescent OLEDs possessing simple device architectures can be fabricated.

This study was supported financially by the National Science Council and Ministry of Economic Affairs of Taiwan.

\section{Notes and references}

1 M. A. Baldo, D. F. O'Brien, Y. You, A. Shoustikov, S. Sibley, M. E. Thompson and S. R. Forrest, Nature, 1998, 395, 151.

2 (a) M. A. Baldo, S. Lamansky, P. E. Burrows, M. E. Thompson and S. R. Forrest, Appl. Phys. Lett., 1999, 75, 4; (b) X. Gong, M. R. Robinson, J. C. Ostrowski, D. Moses, G. C. Bazan and A. J. Heeger, Adv. Mater., 2001, 14, 581; (c) R. J. Holmes, S. R. Forrest, Y.-J. Tung, R. C. Kwong, J. J. Brown, S. Garon and M. E. Thompson, Appl. Phys. Lett., 2003, 82, 2422; (d) S. Tokito, T. Iijima, Y. Suzuri, H. Kita, T. Tsuzuki and F. Sato, Appl. Phys. Lett., 2003, 83, 569; (e) S.-J. Yeh, M.-F. Wu, C.-T. Chen, Y.-H. Song, Y. Chi, M.-H. Ho, S.-F. Hsu and C.-H. Chen, Adv. Mater., 2005, 17, 285; $(f)$ K.-T. Wong, Y.-M. Chen, Y.-T. Lin, H.-C. Su and C.-C. Wu, Org. Lett., 2005, 74, 5361; (g) M.-H. Tsai, H.-W. Lin, H.-C. Su, T.-H. Ke, C.-C. Wu, F.-C. Fang, Y.-L. Liao, K.-T. Wong and C.-I. Wu, Adv. Mater., 2006, 18, 1216; (h) P.-I. Shih, C.-L. Chiang, A. K. Dixit, C.-K. Chen, M.-C. Yuan, R.-Y. Lee, C.-T. Chen, E. W.-G. Diau and C.-F. Shu, Org. Lett., 2006, 8, 27992; (i) M.-H. Tsai, Y.-H. Hong, C.-H. Chang, H.-C. Su, C.-C. Wu, A. Matoliukstyte, J. Simokaitiene, S. Grigalevicius, J. V. Grazulevicius and C.-P. Hsu, Adv. Mater., 2007, 19, 862; (j) D. Tanaka, Y. Agata, T. Takeda, S. Watanabe and J. Kido, Jpn. J. Appl. Phys., 2007, 46, L117; (k) H. J. Bolink, E. Coronado, S. G. Santamaria, M. Sessolo, N. Evans, C. Klein, E. Baranoff, K. Kalyanasundaram, M. Graetzel and M. K. Nazeeruddin, Chem. Commun., 2007, 3276; (l) H. J. Bolink, S. G. Santamaria, S. Sudhakar, C. Zhen and A. Sellinger, Chem. Commun., 2008, 618.

3 (a) D. F. O'Brien, M. A. Baldo, M. E. Thompson and S. R. Forrest, Appl. Phys. Lett., 1999, 74, 442; (b) C. Adachi, M. A. Baldo, S. R. Forrest and M. E. Thompson, Appl. Phys. Lett., 2000, 77, 904; (c) C. Adachi, M. A. Baldo, M. E. Thompson and S. R. Forrest, J. Appl. Phys., 2001, 90, 5048; (d) D. Kolosov, V. Adamovich, P. Djurovich, M. E. Thompson and C. Adachi, J. Am. Chem. Soc., 2002, 124, 9945; (e) H. Inomata, K. Goushi, T. Masuko, T. Konno, T. Imai, H. Sasabe, J. J. Brown and C. Adachi, Chem. Mater., 2004, 16, 1285; $(f)$ P. A. Vecchi, A. B. Padmaperuma, H. Qiao, L. S. Sapochak and P. E. Burrows, Org. Lett., 2006, 8, 4211; $(g)$ M. K. Leung, C. C. Yang, J. H. Lee, H. H. Tsai, C. F. Lin, C. Y. Huang, Y. O. Su and C. F. Chiu, Org. Lett., 2007, 9, 235; (h) H. Kanno, K. Ishikawa, Y. Nishio, A. Endo, C. Adachi and K. Shibata, Appl. Phys. Lett., 2007, 90, 123509.

4 K. T. Wong, Y. L. Liao, Y. T. Lin, H. C. Su and C. C. Wu, Org. Lett., 2005, 7, 5131.

5 T.-C. Chao, Y.-T. Lin, C.-Y. Yang, T. S. Hung, H.-C. Chou, C.-C. Wu and K.-T. Wong, Adv. Mater., 2005, 17, 992.

6 (a) Y.-H. Niu, Y.-L. Tung, Y. Chi, C.-F. Shu, J. H. Kim, B. Chen, J. Luo, A. J. Carty and A. K.-Y. Jen, Chem. Mater., 2005, 17, 3532; (b) T.-H. Liu, S.-F. Hsu, M.-H. Ho, C.-H. Liao, Y.-S. Wu, C. H. Chen, Y.-L. Tung, P.-C. Wu and Y. Chi, Appl. Phys. Lett., 2006, 88, 063508; (c) Y.-L. Tung, L.-S. Chen, Y. Chi, P.-T. Chou, Y.-M. Cheng, E. Y. Li, G.-H. Lee, C.-F. Shu, F.-I. Wu and A. J. Carty, Adv. Funct. Mater., 2006, 16, 1615; (d) J. Kavitha, S.-Y. Chang, Y. Chi, J.-K. Yu, Y.-H. Hu, P.-T. Chou, S.-M. Peng, G.-H. Lee, Y.-T. Tao, C.-H. Chien and A. J. Carty, Adv. Funct. Mater., 2005, 15, 223.

7 (a) C. Adachi, M. A. Baldo and S. R. Forrest, J. Appl. Phys., 2000, 87, 8049; (b) M. A. Baldo, C. Adachi and S. R. Forrest, Phys. Rev. B: Condens. Matter Mater. Phys., 2000, 62, 10967. 